\title{
A revised range of variability approach for the comprehensive assessment of the alteration of flow regime
}

\author{
Chunxue Yu', Xin'an Yin ${ }^{\mathrm{a}}$, Zhifeng Yang ${ }^{\mathrm{a}, *}$
}

a State Key Laboratory of Water Environmental Simulation, School of Environment,

Beijing Normal University. No 19 Xinjiekouwai Street, Beijing, China, 100875

*Correspondence author: Zhifeng Yang.

Tel./fax: +86 10 5880-7951. E-mail: zfyang@bnu.edu.cn. 
Abstract: Assessment of flow regime alteration is significant for the scientific protection and restoration of rivers. The range of variability approach (RVA) and its revised versions, based on a suite of Indicators of Hydrological Alteration (IHA), have been widely used for flow regime alteration assessment. In these methods, the IHA of each specific year are treated separately, and their individual alterations are used to reflect the alteration of flow regime. However, it is known that one hydrological year is an important hydrological period, and the alteration of inner characteristics of one hydrological year (ICOHY), collectively characterized by the 32 IHA values of the year, can also lead to serious ecological degradation of rivers. In other words, treating the 32 IHA individually and separately in RVA and its revisions can not reflect the alteration of ICOHY. To overcome this limitation, a revised RVA is proposed. In the revised method, the 32 IHA values for each specific year are considered as a set, and the alteration of the set (SA) is measured by the set pair analyses method. The assessment of individual alteration (IA) of each IHA is carried out according to RVA. SA and IA are incorporated into a single index to reflect the overall flow regime alteration (OA). The proposed method is applied to a case study of the Xi Dayang Reservoir in China to test its effectiveness. The results suggest that the RVA underestimates the alteration degree and that the new method could give a more comprehensive assessment.

Keywords: Flow regime alteration; Assessment method; Range of variability approach; Set pair analyses. 


\section{Introduction}

The native biodiversity and integrity of riverine ecosystems are dependent on the natural flow regime (Poff et al., 1997). However, climate change and human activities, such as water diversion, dam construction and urban development, have altered the natural flow regime of rivers worldwide (Arthington and Pusey, 2003; Gibson et al., 2005; Arthington et al., 2010; Kennard et al., 2010; Dyer et al., 2014; Wang et al., 2015). Flow regime alteration is regarded as one major cause leading to the degradation of riverine ecosystems (Bunn and Arthington, 2002; Poff et al., 2007). Assessment of flow regime alteration therefore becomes a basic step in designing measures for river protection and restoration ( $\mathrm{Hu}$ et al., 2008; Yin et al., 2011; Shiau and Wu, 2013). Accordingly, effective methods are required to assess flow regime alteration.

The flow regime is usually characterized based on ecologically relevant hydrological indicators derived from river flow data. Depending on the number of hydrological indicators involved, flow regime alteration assessment methods can be categorized as either univariate or multivariable approaches. In univariate approaches, one single hydrological indicator, reflecting one important aspect of the flow regime - such as annual flow, flood frequency or flow duration curves - is adopted, and the ratio of observed value of the indicator to the historic or natural value is regarded as the degree of flow regime alteration (Bunn and Arthington, 2002). The univariate approach is relatively easy to formulate and demonstrate, and has been widely used in riverine research (Olden and Poff, 2003; Bragg et al., 2005; Carlisle et al., 2010). The 
drawback of the univariate approach is that it cannot reflect multiple ecologically significant characteristics of the flow regime. To overcome this problem, researchers have used the multivariable approach to characterize flow regimes (Lake, 2003; Monk et al., 2006; Rheinheimer and Viers, 2014). The range of variability approach (RVA) is the most widely used multivariable approach for the assessment of flow regime alteration (Richter et al., 1996, 1997, 1998; Shiau and Wu, 2007; Yin and Yang, 2011; Yin et al., 2012; Belmar et al., 2013). And many revised versions of RVA are proposed to improve the performance since its origin in 1996 (Suen and Eheart, 2006; Shiau and Wu, 2007, 2008; Yin et al., 2012; Yang et al., 2014; Yin et al., 2015). For example, Shiau and $\mathrm{Wu}$ (2007) used three approaches to calculating the overall degree of hydrological alteration in RVA - the three-class, fuzzy-based, and overall-mean approaches. Yin et al. (2015) coupled the alteration of hydrological year types (i.e. wet, average and dry years) with the traditional RVA. Commonly, in the RVA and its revised versions, a suite of Indicators of Hydrological Alteration (IHA) (including 32 hydrological indicators) is used to characterize each specific hydrological year. The 32 IHAs are categorized by five groups of hydrological features: flow magnitude, duration, timing, frequency and rate of change (Table 1). For each IHA, a range extending from the 25 th to the 75 th percentile (or other metrics, such as histogram dissimilarity (Shiau and $\mathrm{Wu}, 2008)$ ) of the pre-impact indicator value is defined as the target range. The difference between the proportions of pre-impact and post-impact values falling within the target range is considered to represent the alteration of each IHA. Then the 
individual alterations of each IHA are averaged to reflect the overall flow regime alteration.

It clearly can be seen that the commonality of the RVA and its revised versions is that the hydrological indicators for each specific year are treated separately. The 32 IHAs are measured with 32 individual alterations, as shown in Figure 1, and the individual alterations of each IHA are then averaged to reflect the overall flow regime alteration. Nevertheless, certain limitations affect both the RVA and its revised versions. One hydrological year is an important hydrological period, and the 32 IHA values of each specific year collectively characterize the inner characteristics of one hydrological year (ICOHY). The ICOHY are based upon the statistical derivation of whole 32 ecologically relevant hydrological parameters (magnitude, duration, timing, frequency and rates of change) for each year of flow record for the selected reference period or data series (Richter et al., 1996). Yet treating the 32 IHA individually and separately cannot reflect the overall alteration of the ICOHY, and an alteration of the ICOHY can also lead to serious ecological degradation of rivers, even if no individual IHA raises a cause for concern. Hence treating the 32 IHA separately could lead to an underestimation of the flow regime alteration. For example, if there are 100 years of natural flow data for a river, the values of hydrological indicators are correspondingly derived. After regulation, all the 100th percentiles of the IHA annual values are realized in the first year, all the 99th percentiles of the IHA annual values in the second year, ..., and all the 1st percentiles of the IHA annual values in the hundredth year. 
Mathematically, according to the RVA and its variations, the individual alterations of each IHA should equal 0 and the overall flow regime does not change. Obviously, however, the inner characteristics of each hydrological year have been seriously changed, and the regulated flow regime is clearly different from the natural flow regime. Thus, the actual alteration of flow regime should not be equal to 0 , and accordingly the RVA should be improved by taking into account the alteration of the ICOHY.

\section{\#The approximate position of Figure 1\#}

In this study, to overcome the RVA's limitation of neglecting the alteration of ICOHY, a revised RVA is proposed. In this revised method, the 32 IHA values for each specific year are considered as a set, and the alteration of the set is measured by set pair analyses (SPA). The SPA has been successfully applied to many fields, including multi-attribute assessment, forecasting models, and artificial intelligence, and has proved an effective tool for dealing with the set problem (Hu et al., 2008; Su et al., 2009; Wang et al., 2014). The SPA method can be adopted to calculate the alteration of the set of IHAs for each year. Meanwhile, the individual alteration (IA) of each IHA is calculated according to the traditional RVA method. For the sake of brevity, the reader is referred to Richter et al. (1996) for details on the individual assessment of IHAs. The proposed method was used in a case study of the Xi Dayang Reservoir, to test its effectiveness.

\#The approximate position of Table 1\# 


\section{Methodology}

\subsection{The SPA}

The inner characteristics of one hydrological year (ICOHY) are characterized as 32 ecologically relevant IHAs. Each IHA has a value in one hydrological year and they form a data set. The alteration of the set of IHAs for each specific year can be represented as the similarity (dissimilarity) between two data sets (the pre-impact set and the post-impact set). If the pre- and post-impact sets are the same, the alteration between them will be 0 ; if the alteration between them is small, the similarity of the two sets is strong (and dissimilarity is weak). According to existing studies, one can use various distance measures to reflect the similarity (dissimilarity) of the two sets: e.g., Eucledian distance, Chebychev distance, Minkowsky distance (Butina, D., 1999; Lee et al., 2010). However, those methods need to normalize the values of indicators to make the data dimensionless for calculation, and the normalized method might weaken the properties of the indicators. Meanwhile, these methods can only consider one aspect (similarity or dissimilarity) of the two sets and cannot reflect a full view of the characteristics of the two sets.

Set pair analysis (SPA) theory has proved to be an effective tool to deal with the set problem (Su et al., 2009; Wang et al., 2014). It can directly compare the alteration of two sets using the original data of the indicators without data normalization, and the similarity and dissimilarity can be simultaneously represented as the identity and contrary degree of the indicators of the two sets. The SPA also considers the uncertainty 
problem of two sets and uses the discrepancy degree to reflect the uncertain relationship of the two sets. The identity, discrepancy, and contrary (IDC) connection degree functions of the two sets (the set pair) could effectively describe the alteration of the set. Here, SPA was adopted to calculate the alteration of the set of IHAs for each specific year.

Since the details of the method can be found in Jiang et al. (2007), only a brief overview will be provided here. Let set $A$ and relative set $B$ constitute a set pair $\mathrm{H}(A, B)$ of problem H. $n$ terms in $A$-that is, $a_{1}, a_{2}, \ldots, a_{n}$-are used to show the actual characteristics of problem $\mathrm{H}$. Similarly, $n$ terms in $B$ - that is $-b_{1}, b_{2}, \ldots, b_{n}$, are used to show the referenced or normal characteristics of problem. Putting Set $A$ and $B$ together to form Set Pair $\mathrm{H}$ with respect to the problem. To investigate the Set Pair $\mathrm{H}$ and judge its goodness, the connection degree is defined as

$$
\mu_{A-B}=\frac{S}{N}+\frac{F}{N} i+\frac{P}{N} j
$$

where $\mu$ is the connection degree of the set pair; $N$ is the total number of characteristics of the set pair; $S$ denotes the number of identity characteristics; $P$ represents the number of contrary characteristics; and $F=N-S-P$ is the number of characteristics of these two sets that are neither identical nor contrary. $S / N, F / N$, and $P / N$ respectively represent the identity degree, discrepancy degree and contrary degree of the two sets. $j$ is the coefficient of the contrary degree, and is specified as $-1 ; i$, the coefficient of the discrepancy degree, is an uncertain value between -1 and 1 , i.e., $i \in[-1,1]$. 


\subsection{Applications of the SPA method to flow regime alteration assessment}

Using the assessment for the alteration of the set of IHAs for each specific year based on SPA, the problem $\mathrm{H}$ can be defined as follows. $\mathrm{H}=\{\mathrm{R}, \mathrm{P}, \mathrm{Q}\} . \mathrm{P}=\left\{P_{k}\right\}$ and $\mathrm{Q}=\left\{Q_{k}\right\}\left(k=1,2, \ldots, n\right.$, represents the $k^{\text {th }}$ year $)$ are the flow data set of the pre- and post-impact periods, respectively. $\mathrm{R}=\left\{R_{l}\right\}(l=1,2, \ldots)$ is the comparative interval set composed of 32 IHA values. The identity, discrepancy and contrary degrees will be carried out between each of the comparative intervals R for IHAs and the post-impact set of IHAs of each year Q. The connection degree of each year to the corresponding comparative interval is then calculated. The detailed procedure is as follows.

\section{Step 1: Find two relative sets}

Let there be $n$ assessment years and $m$ hydrological indicators. $\mathrm{P}$ and $\mathrm{Q}$ are pre-impact and post-impact sets whose elements are $p_{j k}$ and $q_{j k}$, i.e., $P_{k}=\left\{p_{1 k}, p_{2 k}, \ldots\right.$, $\left.p_{j k}, \ldots, p_{m k}\right\}$ and $Q_{k}=\left\{p_{1 k}, p_{2 k}, \ldots, p_{j k}, \ldots, p_{m k}\right\}(j=1,2, \ldots, m ; k=1,2, \ldots, n)$. For example, if we consider the mean value for January of the years 1970, 1971 and 1972 (3 assessment years) with observed pre- and post-impact values 9.43, 7.20, 6.16 and 4.59, $0.52,0\left(\mathrm{~m}^{3} / \mathrm{s}\right)$ respectively, then $p_{11}=9.43, p_{12}=7.20$ and $p_{13}=6.16$ and $q_{11}=4.59, q_{12}$ $=0.52$ and $q_{13}=0$.

On the other hand, the comparative interval set composed of 32 IHA values $\mathrm{R}=\left\{R_{l}\right\}(l=1,2, \ldots)$, is determined by collecting the management target of IHA based on the pre-impact data P. According to the RAV method (Richter et al., 1997), values at each IHA target range bracketed by the 25th- and 75th-percentile values of the 
pre-impact years were selected for the management target of 32 IHAs. We used the same method to determine the comparative interval. Three comparative intervals can be acquired from the pre-impact sets $P_{k}=\left\{p_{1 k}, p_{2 k}, \ldots, p_{j k}, \ldots, p_{m k}\right\} \quad(j=1,2, \ldots, m ; k=1$, $2, \ldots, n)$ according to 25 th and 75 th percentile values of $m$ hydrological indicators. By collecting the 25th and 75 th percentiles of each hydrological indicator, the comparative intervals can be generated, marked as $P^{25 \text { th }}=\left\{p_{1}^{25 \text { th }}, p_{2}^{25 \text { th }}, \cdots, p_{j}^{25 \text { th }}, \cdots, p_{m}^{25 \text { th }}\right\}$ and $P^{75 \text { th }}=\left\{p_{1}^{75 \text { th }}, p_{2}^{75 \text { th }}, \cdots, p_{j}^{75 \text { th }}, \cdots, p_{m}^{75 \text { th }}\right\}$ respectively representing the 25 th and 75 th percentiles of each hydrological indicator. The comparative intervals can be described as $R_{1}=\left[0, P^{25 \text { th }}\right], R_{2}=\left[P^{25 \text { th }}, P^{75 \text { th }}\right]$ and $R_{3}=\left[P^{75 \text { th }},+\infty\right]$.

For example, considering the mean value of a river for January, if the 25th and 75th percentile values are 5.8 and $8.4 \mathrm{~m}^{3} / \mathrm{s}$, then the critical values of the three comparative intervals for the first index mean value for January are $[0,5.8),[5.8,8.4)$, $[8.4,+\infty)$, respectively.

\section{Step 2: Calculate the connection degree}

The values of $m$ hydrological indicators in the $k^{\text {th }}\left(q_{1 k}, q_{2 k}, \ldots, q_{\mathrm{m} k}\right)$ post-impact year are compared to the comparative interval $\mathrm{R}_{l},\left[0, P^{25 \text { th }}\right],\left[P^{25 \text { th }}, P^{75 \text { th }}\right]$ and $\left[P^{75 \text { th }},+\infty\right]$. The connection degree function of the two sets can be given as follows:

$$
\left(\mu_{P-R}\right)_{k l}=a_{k l}+b_{k l} i+c_{k l} j
$$

where $\left(\mu_{P-Q}\right)_{k l}$ is the connection degree of the $k^{\text {th }}$ year to the $l^{\text {th }}$ comparative interval $(l=1$, $2,3 ; k=1,2, \ldots, n)$; and $a_{k l}, b_{k l}$ and $c_{k l}$ denote the number of identity, discrepancy and contrary characteristics of $k^{\text {th }}$ year to the $l^{\text {th }}$ comparative interval. 
Step 3: Compute the alteration of set of IHAs

Giving equal weight to each year, the alteration of the set of IHAs of each year can be calculated by Equation (4). The coefficient $\mu_{l}$ denotes the connection degree of all $n$ years belonging to the $l^{\text {th }}$ comparative interval, which is computed as

$$
\begin{gathered}
\mu_{l}=\sum_{k=1}^{n} \omega_{l}\left(\mu_{P-R_{l}}\right)_{k l} \\
\mathrm{SA}=\left(1-\frac{\left|\mu_{l=2}\right|}{\left|\mu_{l=1}\right|+\left|\mu_{l=3}\right|}\right) \times 100 \%
\end{gathered}
$$

where SA is the alteration of the set of IHAs.

\section{Step 4: Quantification of overall flow alteration}

The individual alterations (IA) and the alteration of set (SA) are then finally combined to quantify the overall flow regime alteration OA. The core considerations of the revised RVA are that (1) the individual alteration of each IHA and the alteration of the set of 32 IHAs for each specific year both have influence on the ecosystem processes in rivers, (2) the impact of alterations of the set of IHAs on ecosystem processes is no less than the impact of the individual alterations, and (3) the contributions of these two alterations to the overall impact ecosystem processes received from hydrological alteration should be equal. Hence, OA is designed as

$$
\mathrm{OA}=1-[(1-\mathrm{IA}) \times(1-\mathrm{SA})]
$$

\section{Study area}

The Xi Dayang Reservoir is located on the Tang River - the southern branch of the Daqing River, which controls a drainage basin of $4420 \mathrm{~km}^{2}$. The mean annual rainfall of 
the Tang River Basin is about 500 700 mm. The rainfall is unevenly distributed throughout the year: the climate is dry in the spring and autumn and hot and humid in the summer. The location of Xi Dayang Reservoir is shown in Figure 2. It is designed mainly for flood control, irrigation and water supply for the city, but it also provides domestic hydroelectric power. The storage capacity of the Xi Dayang reservoir is 12.58 $\times 10^{8} \mathrm{~m}^{3}$ and the dead storage capacity is $0.799 \times 10^{8} \mathrm{~m}^{3}$. The flood stage is $145.18 \mathrm{~m}$ and dead water level is $120 \mathrm{~m}$. The daily inflow and outflow of the Xi Dayang Reservoir from 1970 to 1991 was adopted in this study as the pre-impact (upstream inflow) and post-impact (downstream outflow) hydrological flow series, respectively, to test the proposed method. The daily inflow was monitored at the Zhongtangmei Station and outflow was monitored in the downstream river of Xi Dayang Reservoir. All data were provided by the Reservoir Administration Bureau of the Xi Dayang Reservoir.

\#The approximate position of Figure 2\#

\section{Results and discussion}

\subsection{Flow regime alteration assessment results using the proposed method}

Based on the collected pre- and post-impact flow data of Xi Dayang Reservoir, we calculated the values of 32 IHAs for each year. Using the proposed model, the IA and SA were calculated. First, the IA was calculated according to the traditional RVA method (the result is shown in Table 2); then, the SA was determined by the SPA method. The coefficient of the discrepancy degree (i), was assumed to equal 0.5 in SPA 
(Jiang et al., 2004; Wang et al., 2009). The identity degree, discrepancy degree and contrary degree of the post-impact indicators to the comparative interval are listed in Table 2, and the IA, SA and overall flow regime alteration OA are shown at the bottom of the table. In general, the overall flow regime OA, considering both the individual and set of IHAs for each year, is $45.73 \%$, which is higher than the hydrological alteration calculated by traditional RVA (33\%). The results suggest that traditional methods underestimate the regulation impact on flow regime, because they neglect the contribution of the SA of the IHAs for each specific year.

Based on Table 2, the connection degrees of each year to three comparative percentile intervals were calculated for Xi Dayang Reservoir from 1970 to 1991. The results are shown in Figure 3a-3c. According to the results of the SPA method, for the three comparative intervals (e.g., $\left[0, \mathrm{P}^{25 \text { th }}\right],\left[\mathrm{P}^{25 \text { th }}, \mathrm{P}^{75 \text { th }}\right]$ and $\left[\mathrm{P}^{75 \text { th }},+\infty\right)$, the connection degrees of each post-impact year differ from the others. The SPA has a rule that the closer the value of connection degree to 1 , the more similar the two sets. It is clear that the values of the connection degree of all the years are smoother in the interval $\left[\mathrm{P}^{25 t h}\right.$, $\left.\mathrm{P}^{75 \text { th }}\right]$ than in the other two intervals. Meanwhile, the connection degrees of all the years in interval of $\left[\mathrm{P}^{75 \text { th }},+\infty\right)$ are almost all below zero, which indicates that high positive and flood events in the river are largely regulated. That result suggests that the SPA could effectively represent the alteration of set (SA) of the 32 IHAs for each specific year, and clearly indicates a regulated hydrological event. This information could be very helpful for the river management. The alteration of set (CA) of the 32 IHAs for 
each year is essential to the survival, growth, and reproduction of aquatic species. Therefore, to better reflect the flow regime alteration, the alteration of the set of hydrological indicators needs to be considered.

\#The approximate position of Table 2\#

\#The approximate position of Figure 3\#

\subsection{Sensitivity comparison between the RVA and the new method}

To compare the sensitivity of the proposed method and traditional RVA, we designed five scenarios (each with 8 members) by changing the order of the pre-impact IHAs, which were calculated based on the natural inflow data of Xi Dayang Reservoir from 1970 to 1991 (22 years). For Scenario I, we change the order of all indicators in Group 1 as shown in Table 1 . Member 1, the first post-impact indicators series, is the same as the pre-impact series (number of exchanged years $=0$ ). For Member 2, we exchanged the $1^{\text {st }}$ and $22^{\text {nd }}$ years (number of exchanged years $=2$ ). For Member 3 , we also exchanged the $2^{\text {nd }}$ and $21^{\text {st }}$ years (number of exchanged years $=4$ ), and so on (Figure 4). Each additional series therefore involved changing an additional pair of years so that the number of exchanges increased from 0 in the first post-impact series to 22 in the last post-impact series. The remaining four scenarios were designed to exchange the indicators in Group 2, 3, 4 and 5 in the same way as for Group 1 (Figure 4). There are 5 designed Scenarios and each Scenario has 8 members. In general, the two methods are carried out $40(5 \times 8)$ times to test their sensitivity.

\#The approximate position of Figure 4\# 
We used the RVA and the newly established method in this paper to calculate the alteration of the overall flow regime in the five designed scenarios $(5 \times 8=40$ members $)$; the results are shown in Table 3. In the results using RVA, the overall degree of the flow regime alteration was constant at 0 , regardless of the exchanged IHAs for each year. However, when considering the alteration of set (SA) of IHAs for each year, the overall flow regime was never equal to 0 . As the number of exchanged indicators increased in each scenario, the SA and the overall flow regime alteration (OA) generally increased. In Table 3, it is clear that the flow regime alteration was greater in Scenarios I and II (with more indicators) than in the other three scenarios, indicating that the flow regime was obviously influenced by SA. In fact, the SA of 32 of the IHAs for each specific year could have been caused by extreme flow events such as droughts and floods, or by reservoir conditions. Thus, if the SA is modified, the degree of the overall flow regime alteration should not be equal to 0 .

\#The approximate position of Table 3\#

In the above analysis, we adopted commonly used quantiles of IHAs values in the RVA method to obtain three comparative intervals- $\left[0, P^{25 \text { th }}\right],\left[P^{25 \text { th }}, P^{75 \text { th }}\right]$ and $\left[P^{75 \text { th }}\right.$, $+\infty)$. To further test the sensitivity of the proposed method, the number of comparative intervals was increased to $4\left(\left[0, P^{25 \text { th }}\right],\left[P^{25 \text { th }}, P^{50 \text { th }}\right],\left[P^{50 \text { th }}, P^{75 \text { th }}\right]\right.$ and $\left.\left[P^{75 \text { th }},+\infty\right]\right), 5([0$, $\left.\left.P^{20 \text { th }}\right],\left[P^{20 \text { th }}, P^{40 \text { th }}\right], \ldots,\left[P^{80 \text { th }},+\infty\right)\right), 8\left(\left[0, P^{12.5 \text { th }}\right],\left[P^{12.5 \text { th }}, P^{25 \text { th }}\right], \ldots,\left[P^{87.5 \text { th }},+\infty\right)\right), 10([0$, $\left.\left.P^{10 \text { th }}\right],\left[P^{10 \text { th }}, P^{20 \text { th }}\right], \ldots,\left[P^{90 \text { th }},+\infty\right)\right), 16\left(\left[0, P^{6.25 \text { th }}\right],\left[P^{6.25 \text { th }}, P^{12.5 \text { th }}\right], \ldots,\left[P^{93.75 \text { th }},+\infty\right)\right)$, and $20\left(\left[0, P^{5 \text { th }}\right],\left[P^{5 \text { th }}, P^{100 \text { th }}\right], \ldots,\left[P^{95 \text { th }},+\infty\right)\right)$. We focus here only on the proposed 
method combined the RVA and SPA to do the comparison work, to check the influence of the number of comparative intervals. Using the flow data of Xi Dayang reservoir, the pre-impact flow series was defined in the same way as the post-impact series. The results are shown as Figure 5, which reveals that although the pre- and post- impact flow was the same, the overall flow regime could be slightly changed depending on the method chosen. Since some of the IHA values were equal to the boundary values of the comparative intervals, the number of IHAs falling into the comparative intervals (target) was decreased, thereby influencing the results of the overall flow regime alteration. Figure 5 also shows a variation in the overall flow regime alteration depending on the different number of comparative intervals. As the number of comparative intervals increased, the overall degree of the flow regime increased, indicating that varying the numbers of comparative intervals influenced the results of the proposed method. Having more comparative intervals decreases the widths of the comparative intervals, causing the IHA data to be too scattered, as many of the indicators are at the boundary values of the intervals. The connection degree function of two set pairs would then be too vaguely built and the final calculation of flow regime alteration would be changed. Thus, the optimal number of the comparative intervals needs to be carefully selected.

\#The approximate position of Figure 5\#

\subsection{Uncertainty of the discrepancy coefficient $i$ in the proposed method}

SPA theory (Jiang et al., 2004) identifies two parts of the symmetry information: certainty (identify degree a, discrepancy degree b and contrary degree c) and uncertainty 
( $i$, the coefficient of the discrepancy degree). The value of $i$ can have a significant influence on the final results, and has been defined in various ways in the published literature (Wang et al., 2009; Su et al., 2009; Wang et al., 2014). Usually it is defined as an uncertainty value between 0.2 and 0.5 , i.e., $i \in[0.2,0.5]$, although in fact the value of $i$ includes the full range between -1 and $1 i \in[-1,1]$. In order check the influence of the discrepancy degree (bi) on the flow regime alteration assessment, however, the proposed method, using SPA theory, was conducted under varying values of coefficient $i$. We defined 0.2 and 0.5 as the extreme values of the coefficient $i$. Since in our study the width of every sampling interval was 0.02 (i.e., $i=(0.2,0.22,0.24, \ldots, 0.48,0.5))$, there were sixteen possible values for $i$. To test the sensitivity of parameter $i$, the other conditions were set as unchanged; i.e., the post-impact time series was the same as the pre-impact series.

The flow regime alteration under the different values of $i$ is expressed in Figure 6. It is clear that the overall flow regime is but slightly influenced by the value of $i$. From $i=0.2$ to 0.5 , the overall flow regime alteration showed a slight fluctuation, and the regime reached its minimum alteration, zero, at $i=0.4$ and 0.5 . Since in this study the uncertainty information $(i)$ was assumed as 0.5 , and the pre- and post- impact flows were the same, the flow regime alteration equaled 0 , indicating that the value of 0.5 for $i$ is suitable for the assessment of flow regime alteration. Hence $i$ is still an important parameter in the revised RVA, as it controls the uncertainty of ecologically relevant hydrological indicators and the comparative intervals, and it is recommended that future 
users carefully select the $i$ value that identifies most of the uncertainty of the set pairs.

\section{\#The approximate position of Figure 6\#}

\subsection{Model Limitations}

It is important to recognize the applicable environments of proposed method when trying to apply it into practical implications. The revised RVA method may still not precisely characterize the hydrological alteration. In the proposed method, some components, for example, the definition of the discrepancy coefficient $i$, are subjective based on the experience of existing studies. There is no experimental basis or enough ecological data for us to judge the relationship of ecosystems and flow regime; thus, problems about the subjective definition of some components will always exist in the assessment method of flow regime alteration. In this study, we propose to take the alteration of inner characteristics of one hydrological year into account through a revised RVA. Compared with the traditional RVA and its refined versions, this new method provides better estimation of hydrological alteration. Future development of more ecological-based methods and better definition of the discrepancy coefficient $i$ will contribute to the applicability of the proposed method.

The proposed method is suitable for flow regime alteration assessment in any other cases as the traditional RVA method can. Application of the revised RVA in this paper would further reduce the flexibility of river management for socioeconomic interests, due to the revised approach gives a more comprehensive assessment of flow regime alteration. For some rivers, in particular for where riverine ecosystem has not been 
suitably protected during the past, the managers might need to renegotiate the trade-offs in different management options. Although the proposed method gives a severe task on practical river management, it will also help to expand the definition of the sustainable use of the river systems.

\section{Conclusion}

The traditional RVA and the revised RVA methods both consider only the individual alterations of IHAs to reflect the flow regime, neglecting that the alteration of the set of 32 IHAs for each specific year could influence the regime. The integration and quantification of the alteration of the set of 32 IHAs is crucial to comprehensively assessing the flow regime alteration, which can be helpful for the protection and restoration of the ecological integrity of regulated river ecosystems. In this study, we proposed a new method incorporating both individual and sets of alterations of IHAs. The individual alteration was determined according to the traditional RVA method. The set of alterations of IHAs is reflected by the connection degree function of the set pair of IHAs. Compared with the traditional RVA and its alternatives, the proposed method could give a more comprehensive representation of hydrological alteration caused by human and natural impacts. Thus, better protection of an ecosystem might be obtained by applying this method in the management of rivers. We used actual and rearranged series of IHAs to demonstrate the effectiveness of the proposed method and reached the following conclusions: 
- The case study of the Xi Dayang Reservoir and rearranged IHAs suggests that the traditional RVA underestimates hydrological alterations because it neglects the set of alterations of 32 IHAs for each specific year, whereas the proposed method overcomes this limitation. This new method provides a more comprehensive assessment of hydrological alteration.

- The choice of discrepancy degree $i$ is important for the proposed method, because it could affect both the mean state and the uncertainty of the entire alteration. Future users should give careful consideration to choosing the number of comparative intervals and a suitable coefficient $i$ of discrepancy degree, when using this proposed method.

\section{ACKNOWLEDGEMENTS}

This research was supported by the National Natural Science Foundation of China (No. 51439001), the National Science Foundation for Innovative Research Group (No. 51421065), and the International Science \& Technology Cooperation Program of China (No. 2011DFA72420).

\section{References:}

Arthington, A.H., Pusey, B.J., 2003. Flow restoration and protection in Australian rivers. River Research and Applications, 19(5-6), 377-395.

Arthington, A.H., Robert, J.N., Michael, E.M., et al., 2010. Preserving the biodiversity 
and ecological services of rivers: new challenges and research opportunities. Freshwater Biology, 55(1), 1-16.

Belmar, O., Bruno, D., Martinez-Capel, F., et al., 2013. Effects of flow regime alteration on fluvial habitats and riparian quality in a semiarid Mediterranean basin. Ecological Indicators, 30, 52-64.

Bragg, O.M., Black, A.R., Duck, R.W., et al., 2005. Approaching the physical-biological interface in rivers: a review of methods for ecological evaluation of flow regimes. Progress in Physical Geography, 29(4), 506-531.

Bunn, S.E., Arthington, A.H., 2002. Basic principles and ecological consequences of altered flow regimes for aquatic biodiversity. Environmental Management, 30(4), 492-507.

Butina, D., 1999. Unsupervised data base clustering based on daylight's fingerprint and Tanimoto similarity: A fast and automated way to cluster small and large data sets. Journal of Chemical Information and Computer Sciences, 39(4), 747-750.

Carlisle, D.M., Wolock, D.M., Meador, M.R., 2010. Alteration of streamflow magnitudes and potential ecological consequences: a multiregional assessment. Frontiers in Ecology and the Environment, 9(5), 264-270.

Dyer, F., ElSawah, S., Croke, B., et al., 2014. The effects of climate change on ecologically-relevant flow regime and water quality attributes. Stochastic Environmental Research and Risk Assessment, 28(1), 67-82.

Gibson, C.A., Meyer, J.L., Poff, N.L., et al., 2005. Flow regime alterations under 
changing climate in two river basins: implications for freshwater ecosystems. River Research and Applications, 21(8), 849-864.

Hu, W.W., Wang, G.X., Deng, W., et al., 2008. The influence of dams on ecohydrological conditions in the Huaihe River basin, China. Ecological engineering, 33(3), 233-241.

Hu, X.X., Yang, X.H., Li, J.Q., et al., 2008. Set pair analysis model for river health system assessment. Systems Engineering-Theory \& Practice, 5, 164-176.

Jiang, Y.L., Xu, C.F., Yao, Y., et al., 2004. Systems information in set pair analysis and its applications. In Machine Learning and Cybernetics. Proceedings of 2004 International Conference, 3, 1717-1722.

Kennard, M.J., Pusey, B.J., Olden, J.D., et al., 2010. Classification of natural flow regimes in Australia to support environmental flow management. Freshwater Biology, 55(1), 171-193.

Lake, P.S., 2003. Ecological effects of perturbation by drought in flowing waters. Freshwater Biology, 48(7), 1161-1172.

Lee, K.H., Lee, Y.J., Choi, H., et al., 2012. Parallel data processing with MapReduce: a survey. AcM sIGMoD Record, 40(4), 11-20.

Monk, W.A., Wood P.J., Hannah, D.M., et al., 2006. Flow variability and macroinvertebrate community response within riverine systems. River Research and Applications, 22(5), 595-615.

Olden, J.D., Poff, N.L., 2003. Redundancy and the choice of hydrologic indices for 
characterizing streamflow regimes. River Research and Applications, 19(2), $101-121$

Poff, N.L., Allan, J.D., Bain, M.B., et al., 1997. The natural flow regime. BioScience, 47(11), 769-784.

Poff, N.L., Olden, J.D., Merritt, D.M., et al., 2007. Homogenization of regional river dynamics by dams and global biodiversity implications. Proceedings of the National Academy of Sciences, 104(14), 5732-5737.

Rheinheimer, D. E., Viers, J.H., 2014. Combined effects of reservoir operations and climate warming on the flow regime of hydropower bypass reaches of California's sierra nevada. River Research and Applications, 31, 269-279.

Richter, B.D., Baumgartner, J.V., Braun, D.P., et al., 1998. A spatial assessment of hydrologic alteration within a river network. River Research and Applications, 14(4), 329-340.

Richter, B.D., Baumgartner, J.V., Powell, J., et al., 1996. A method for assessing hydrologic alteration within ecosystems. Conservation Biology, 10(4), 1163-1174.

Richter, B.D., Baumgartner, J.V., Wigington, R., et al., 1997. How much water does a river need?. Freshwater Biology, 37(1), 231-249.

Shiau, J.T., Wu, F.C., 2007. A dynamic corridor-searching algorithm to seek time-varying instream flow releases for optimal weir operation: comparing three indices of overall hydrologic alteration. River Research and Applications, 23(1), $35-53$. 
Shiau, J.T., Wu, F.C., 2008. A histogram matching approach for assessment of flow regime alteration: application to environmental flow optimization. River research and applications, 24(7), 914-928.

Shiau, J.T., Wu, F.C., 2013. Optimizing environmental flows for multiple reaches affected by a multipurpose reservoir system in Taiwan: Restoring natural flow regimes at multiple temporal scales. Water Resources Research, 49(1), 565-584.

Su, M.R., Yang, Z.F., Chen, B., et al., 2009. Urban ecosystem health assessment based on flow and set pair analysis-A comparative study of typical Chinese cities. Ecological Modelling, 220(18), 2341-2348.

Suen, J.P., Eheart, J.W., 2006. Reservoir management to balance ecosystem and human needs: incorporating the paradigm of the ecological flow regime. Water Resources Research, 42. DOI:10.1029/2005WR004314.

Wang, M.W., Xu, P., Li, J., et al., 2014. A novel set pair analysis method based on variable weights for liquefaction evaluation. Natural Hazards, 70(2), 1527-1534.

Wang, W., Jin, J., Ding, J., et al., 2009. A new approach to water resources system assessment — set pair analysis method. Science in China Series E: Technological Sciences, 52(10), 3017-3023.

Wang, Y., Wang, D., Wu, J., 2015. Assessing the impact of Danjiangkou reservoir on ecohydrological conditions in Hanjiang river, China. Ecological Engineering, 81, $41-52$.

Yang, P., Yin, X.A., Yang, Z.F., et al., 2014. A revised range of variability approach 
considering the periodicity of hydrological indicators. Hydrological Processes, 28(26), 6222-6235.

Yin, X.A., Yang, Z.F., Petts, G.E., 2011. Reservoir operating rules to sustain environmental flows in regulated rivers. Water Resources Research, 47, W08509. DOI: $10.1029 / 2010 w r 009991$.

Yin, X.A., Yang, Z.F., Petts, G.E., 2012. Optimizing environmental flows below dams. River Research and Applications, 28(6), 703-716.

Yin, X.A., Yang, Z.F., Petts, G.E., 2015. A new method to assess the flow regime alterations in riverine ecosystems. River Research and Applications, 31(4), 497-504. 


\section{Figure captions}

Figure 1 The core idea of the proposed method. (1) The traditional RVA and its refined versions treat the IHAs of each year separately to calculate their alteration (Lateral distance, the calculation of IA); (2) The new proposed method not only consider the individual alteration of IHAs (Lateral distance, the calculation of IA), but also take the alteration of the set (SA) (Longitudinal distance, the calculation of SA) into account. Both the alteration of the set (SA) and individual alteration (IA) of each IHA could lead to the degradation of ecosystem.

Figure 2 Location of the Xi Dayang Reservoir

Figure 3 Connection degrees of three comparative intervals for Xi Dayang reservoir

Figure 4 Framework used in the sensitivity analysis

Figure 5 Relationship between the number of comparative intervals and the flow regime alteration

Figure 6 Sensitivity comparison of different values of coefficient $i$ of discrepancy degree 
Figure 1

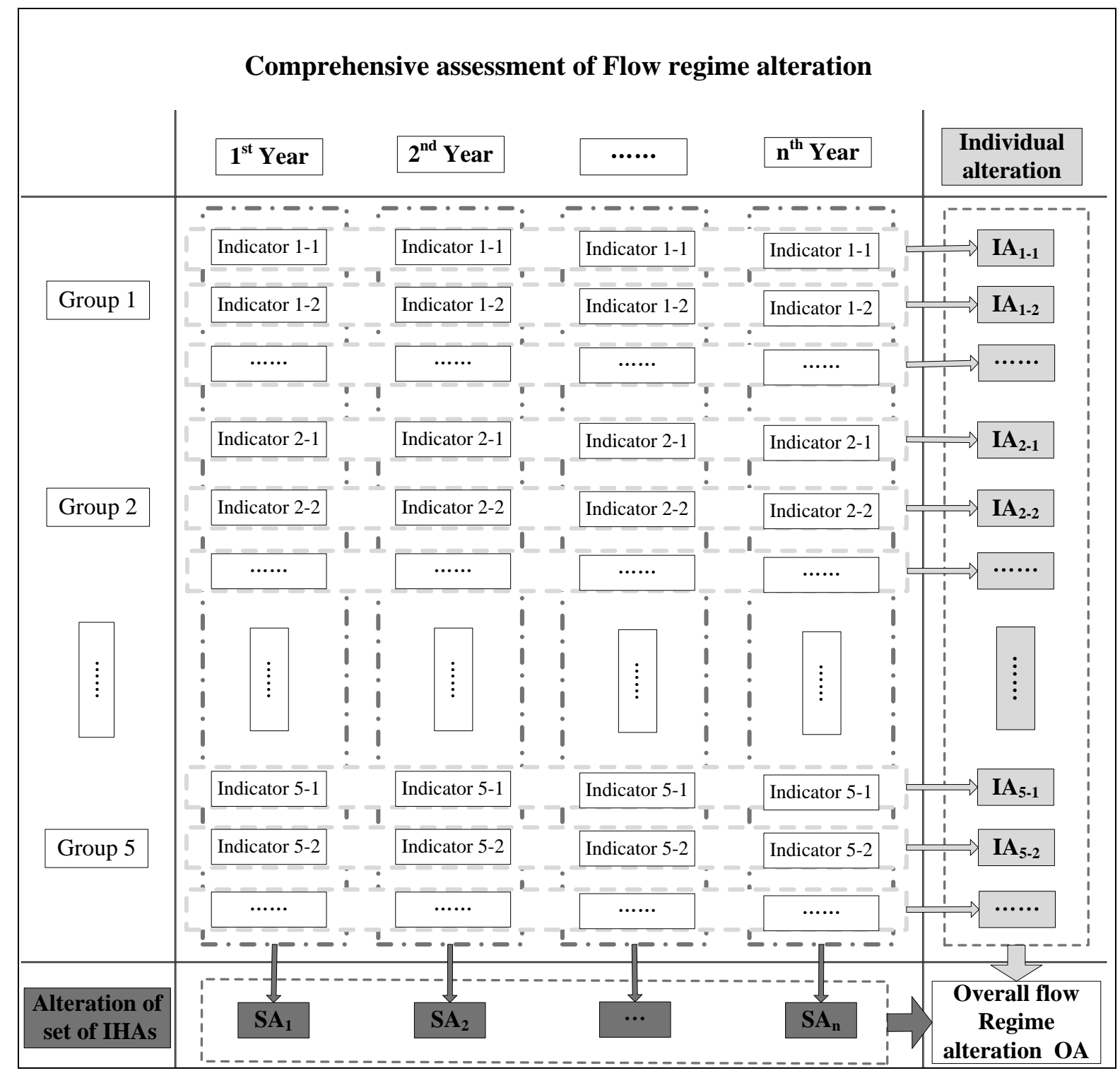


Figure 2

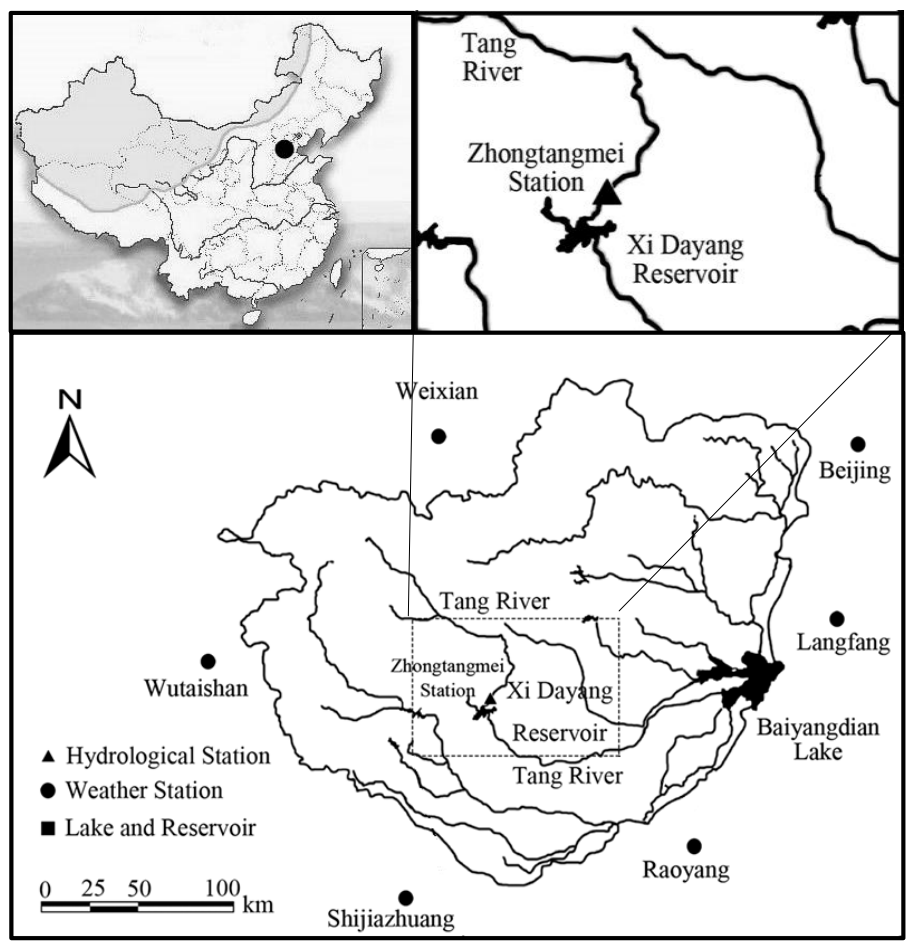


Figure 3
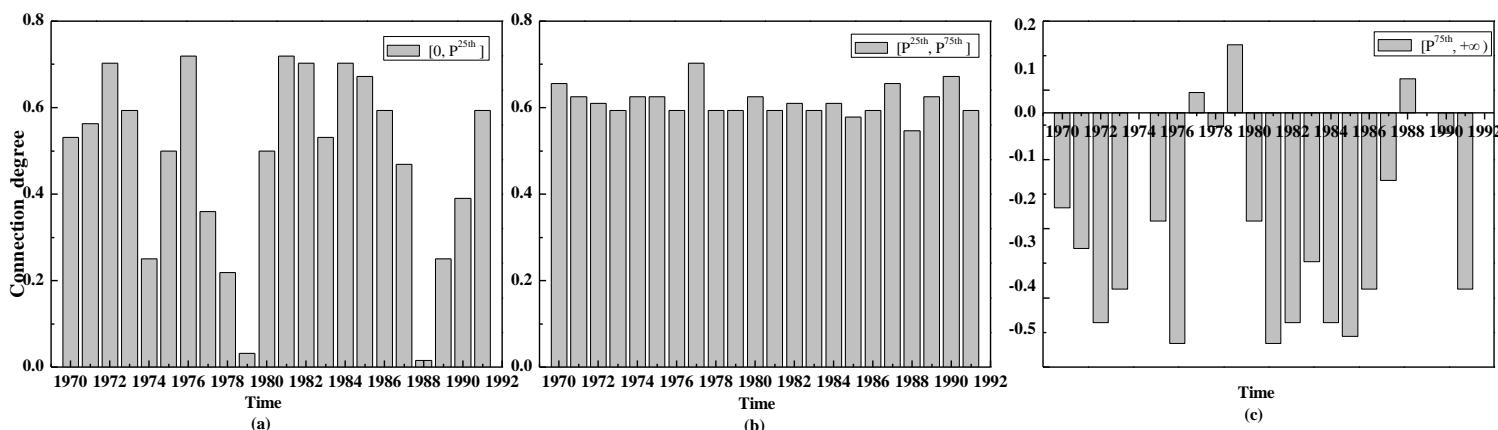
Figure 4

\begin{tabular}{|c|c|c|c|c|c|c|c|c|c|}
\hline $\begin{array}{l}\text { Pre-impact } \\
\text { indicators }\end{array}$ & $\begin{array}{l}\begin{array}{l}\text { IHAs of } \\
\text { the } 1^{\text {st }} \text { year }\end{array} \\
\end{array}$ & \begin{tabular}{|l|} 
IHAs of \\
the $2^{\text {nd }}$ year
\end{tabular} & $\begin{array}{l}\text { IHAs of } \\
\text { the } 3^{\text {rd }} \text { year }\end{array}$ & & $\ldots \ldots$ & & $\begin{array}{l}\begin{array}{l}\text { IHAs of the } \\
20^{\text {th }} \text { year }\end{array} \\
\end{array}$ & $\begin{array}{l}\text { IHAs of the } \\
21^{\text {th }} \text { year }\end{array}$ & $\begin{array}{l}\text { IHAs of the } \\
22^{\text {th }} \text { year }\end{array}$ \\
\hline $\begin{array}{l}\text { Pre-impact } \\
\text { Scenario I }\end{array}$ & $\begin{array}{l}\text { G1 of the } \\
1^{\text {st }} \text { year }\end{array}$ & $\begin{array}{l}\text { G1 of the } \\
2^{\text {nd }} \text { year }\end{array}$ & $\begin{array}{l}\text { G1 of the } \\
3^{\text {rd }} \text { year }\end{array}$ & $\Delta$ & & $\Delta$ & $\begin{array}{l}\text { G1 of the } \\
20^{\text {th }} \text { year }\end{array}$ & $\begin{array}{l}\text { G1 of the } \\
21^{\text {th }} \text { year }\end{array}$ & $\begin{array}{l}\text { G1 of the } \\
22^{\text {th }} \text { year }\end{array}$ \\
\hline $\begin{array}{l}\text { Pre-impact } \\
\text { Scenario II }\end{array}$ & $\begin{array}{l}\text { G2 of the } \\
1^{\text {st }} \text { year }\end{array}$ & $\begin{array}{l}\text { G2 of the } \\
2^{\text {nd }} \text { year }\end{array}$ & $\begin{array}{l}\text { G2 of the } \\
3^{\text {rd }} \text { year }\end{array}$ & $\Delta$ & & $\Delta$ & $\begin{array}{l}\text { G2 of the } \\
20^{\text {th }} \text { year }\end{array}$ & $\begin{array}{l}\text { G2 of the } \\
21^{\text {th }} \text { year }\end{array}$ & $\begin{array}{l}\mathrm{G} 2 \text { of the } \\
22^{\text {th }} \text { year }\end{array}$ \\
\hline $\begin{array}{l}\text { Pre-impact } \\
\text { Scenario V }\end{array}$ & $\begin{array}{l}\mathrm{G} 5 \text { of the } \\
1^{\text {st }} \text { year }\end{array}$ & \begin{tabular}{|l} 
G5 of the \\
$2^{\text {nd }}$ year
\end{tabular} & $\begin{array}{l}\text { G5 of the } \\
3^{\text {rd }} \text { year }\end{array}$ & $\Delta$ & $\cdots$ & $\Delta$ & \begin{tabular}{|l} 
G5 of the \\
$20^{\text {th }}$ year
\end{tabular} & $\begin{array}{l}\text { G5 of the } \\
21^{\text {th }} \text { year }\end{array}$ & $\begin{array}{l}\text { G5 of the } \\
22^{\text {th }} \text { year }\end{array}$ \\
\hline
\end{tabular}


Figure 5

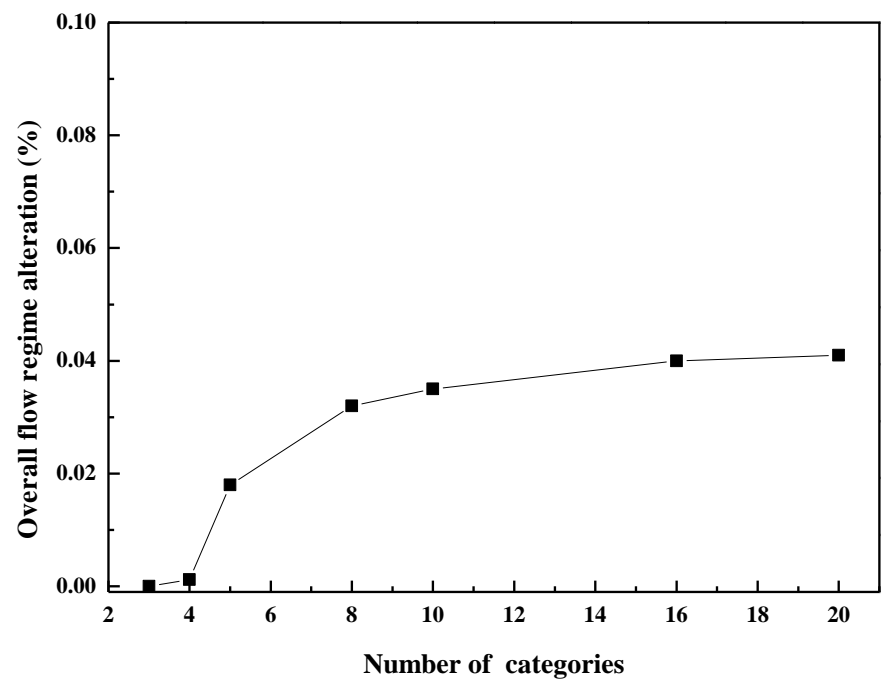


Figure 6

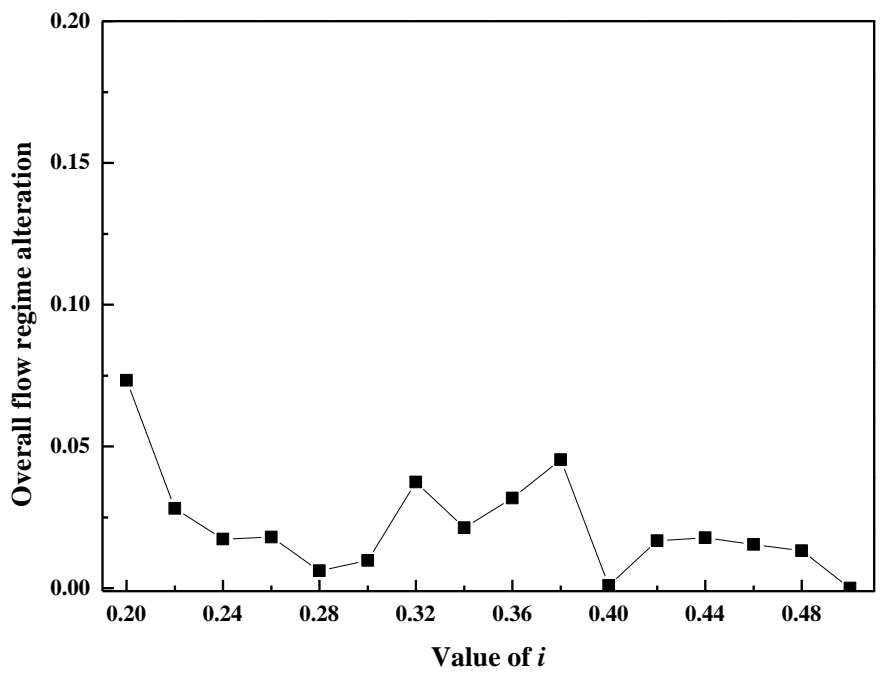




\section{Table captions}

Table 1 Indicators of hydrological alteration (IHA) in the range of variability approach

Table 2 The IDC and connective degree of IHAs and degree of flow regime alteration

Table 3 Flow regime alteration for both the traditional RVA method and the proposed method, for the five designed scenarios 
Table 1

\begin{tabular}{|c|c|}
\hline IHA group & Hydrological indicators \\
\hline $\begin{array}{l}\text { Group 1: Magnitude of monthly water } \\
\text { conditions }\end{array}$ & Mean value for each calendar month \\
\hline $\begin{array}{l}\text { Group 2: Magnitude and duration of annual } \\
\text { extreme water conditions }\end{array}$ & $\begin{array}{l}\text { Annual minima 1-day means } \\
\text { Annual maxima 1-day means } \\
\text { Annual minima 3-day means } \\
\text { Annual maxima 3-day means } \\
\text { Annual minima 7-day means } \\
\text { Annual maxima 7-day means } \\
\text { Annual minima 30-day means } \\
\text { Annual maxima 30-day means } \\
\text { Annual minima 90-day means } \\
\text { Annual maxima 90-day means }\end{array}$ \\
\hline $\begin{array}{l}\text { Group 3: Timing of annual extreme water } \\
\text { conditions }\end{array}$ & $\begin{array}{l}\text { Julian date of each annual 1-day maximum } \\
\text { Julian date of each annual 1-day minimum }\end{array}$ \\
\hline $\begin{array}{l}\text { Group 4: Frequency and duration of high and } \\
\text { low pulses }\end{array}$ & $\begin{array}{l}\text { No. of high pulses each year } \\
\text { No. of low pulses each year } \\
\text { Mean duration of high pulses within each year } \\
\text { Mean duration of low pulses within each year }\end{array}$ \\
\hline $\begin{array}{l}\text { Group 5: Rate and frequency of water } \\
\text { condition changes }\end{array}$ & $\begin{array}{l}\text { Means of all positive differences between consecutive daily means } \\
\text { Means of all negative differences between consecutive daily values } \\
\text { No. of rises } \\
\text { No. of falls }\end{array}$ \\
\hline
\end{tabular}


Table 2

\begin{tabular}{|c|c|c|c|c|c|c|c|c|c|c|c|c|}
\hline \multirow{2}{*}{ Year } & \multirow{2}{*}{$\mathrm{S}$} & \multirow{2}{*}{$\mathrm{F}$} & \multirow{2}{*}{$\mathrm{P}$} & \multicolumn{3}{|c|}{$\left[0, \mathrm{P}^{25 \text { th }}\right]$} & \multicolumn{3}{|c|}{$\left[\mathrm{P}^{25 \text { th }}, \mathrm{P}^{75 \text { th }}\right]$} & \multicolumn{3}{|c|}{$\left[\mathrm{P}^{75 \text { th }},+\infty\right)$} \\
\hline & & & & $\mathrm{a}$ & $\mathrm{b}$ & $\mathrm{c}$ & $\mathrm{a}$ & $\mathrm{b}$ & $\mathrm{c}$ & a & $\mathrm{b}$ & c \\
\hline 1970 & 17 & 10 & 5 & 0.5313 & 0.313 & 0.1563 & 0.3125 & 0.6875 & 0 & 0.15625 & 0.3125 & 0.53125 \\
\hline 1971 & 19 & 8 & 5 & 0.5938 & 0.25 & 0.1563 & 0.25 & 0.75 & 0 & 0.15625 & 0.25 & 0.59375 \\
\hline 1972 & 22 & 7 & 3 & 0.6875 & 0.219 & 0.0938 & 0.21875 & 0.78125 & 0 & 0.09375 & 0.21875 & 0.6875 \\
\hline 1973 & 21 & 6 & 5 & 0.6563 & 0.188 & 0.1563 & 0.1875 & 0.8125 & 0 & 0.15625 & 0.1875 & 0.65625 \\
\hline 1974 & 14 & 8 & 10 & 0.4375 & 0.25 & 0.3125 & 0.25 & 0.75 & 0 & 0.3125 & 0.25 & 0.4375 \\
\hline 1975 & 18 & 8 & 6 & 0.5625 & 0.25 & 0.1875 & 0.25 & 0.75 & 0 & 0.1875 & 0.25 & 0.5625 \\
\hline 1976 & 23 & 6 & 3 & 0.7188 & 0.188 & 0.0938 & 0.1875 & 0.8125 & 0 & 0.09375 & 0.1875 & 0.71875 \\
\hline 1977 & 12 & 13 & 7 & 0.375 & 0.406 & 0.2188 & 0.40625 & 0.59375 & 0 & 0.21875 & 0.40625 & 0.375 \\
\hline 1978 & 15 & 6 & 11 & 0.4688 & 0.188 & 0.3438 & 0.1875 & 0.8125 & 0 & 0.34375 & 0.1875 & 0.46875 \\
\hline 1979 & 12 & 6 & 14 & 0.375 & 0.188 & 0.4375 & 0.1875 & 0.8125 & 0 & 0.4375 & 0.1875 & 0.375 \\
\hline 1980 & 18 & 8 & 6 & 0.5625 & 0.25 & 0.1875 & 0.25 & 0.75 & 0 & 0.1875 & 0.25 & 0.5625 \\
\hline 1981 & 23 & 6 & 3 & 0.7188 & 0.188 & 0.0938 & 0.1875 & 0.8125 & 0 & 0.09375 & 0.1875 & 0.71875 \\
\hline 1982 & 22 & 7 & 3 & 0.6875 & 0.219 & 0.0938 & 0.21875 & 0.78125 & 0 & 0.09375 & 0.21875 & 0.6875 \\
\hline 1983 & 20 & 6 & 6 & 0.625 & 0.188 & 0.1875 & 0.1875 & 0.8125 & 0 & 0.1875 & 0.1875 & 0.625 \\
\hline 1984 & 22 & 7 & 3 & 0.6875 & 0.219 & 0.0938 & 0.21875 & 0.78125 & 0 & 0.09375 & 0.21875 & 0.6875 \\
\hline 1985 & 23 & 5 & 4 & 0.7188 & 0.156 & 0.125 & 0.15625 & 0.84375 & 0 & 0.125 & 0.15625 & 0.71875 \\
\hline 1986 & 21 & 6 & 5 & 0.6563 & 0.188 & 0.1563 & 0.1875 & 0.8125 & 0 & 0.15625 & 0.1875 & 0.65625 \\
\hline 1987 & 16 & 10 & 6 & 0.5 & 0.313 & 0.1875 & 0.3125 & 0.6875 & 0 & 0.1875 & 0.3125 & 0.5 \\
\hline 1988 & 14 & 3 & 15 & 0.4375 & 0.094 & 0.4688 & 0.09375 & 0.90625 & 0 & 0.46875 & 0.09375 & 0.4375 \\
\hline 1989 & 14 & 8 & 10 & 0.4375 & 0.25 & 0.3125 & 0.25 & 0.75 & 0 & 0.3125 & 0.25 & 0.4375 \\
\hline 1990 & 14 & 11 & 7 & 0.4375 & 0.344 & 0.2188 & 0.34375 & 0.65625 & 0 & 0.21875 & 0.34375 & 0.4375 \\
\hline 1991 & 21 & 6 & 5 & 0.6563 & 0.188 & 0.1563 & 0.1875 & 0.8125 & 0 & 0.15625 & 0.1875 & 0.65625 \\
\hline SA & & & & & $19 \%$ & & & & & & & \\
\hline IA & & & & & $33 \%$ & & & & & & & \\
\hline OA & & & & & $45.73 \%$ & & & & & & & \\
\hline
\end{tabular}


Table 3

\begin{tabular}{|c|c|c|c|c|c|c|c|c|c|c|c|c|c|c|c|}
\hline \multirow{2}{*}{ Exchanged years } & \multicolumn{3}{|c|}{ Scenario I } & \multicolumn{3}{|c|}{ Scenario II } & \multicolumn{3}{|c|}{ Scenario III } & \multicolumn{3}{|c|}{ Scenario IV } & \multicolumn{3}{|c|}{ Scenario V } \\
\hline & $\mathrm{CA}$ & IA & $\mathrm{OA}$ & $\mathrm{CA}$ & IA & $\mathrm{OA}$ & $\mathrm{CA}$ & IA & $\mathrm{OA}$ & $\mathrm{CA}$ & IA & $\mathrm{OA}$ & $\mathrm{CA}$ & IA & $\mathrm{OA}$ \\
\hline 2 & $4.8 \%$ & 0 & $4.8 \%$ & $5.66 \%$ & 0 & $5.66 \%$ & $0.98 \%$ & 0 & $0.98 \%$ & $0.5 \%$ & 0 & $0.5 \%$ & $1.1 \%$ & 0 & $1.1 \%$ \\
\hline 4 & $5.4 \%$ & 0 & $5.4 \%$ & $6.49 \%$ & 0 & $6.49 \%$ & $0.33 \%$ & 0 & $0.33 \%$ & $0.5 \%$ & 0 & $0.5 \%$ & $1.57 \%$ & 0 & $1.57 \%$ \\
\hline 6 & $8.4 \%$ & 0 & $8.4 \%$ & $9.64 \%$ & 0 & $9.64 \%$ & $0.69 \%$ & 0 & $0.69 \%$ & $0.11 \%$ & 0 & $0.11 \%$ & $2.03 \%$ & 0 & $2.03 \%$ \\
\hline 8 & $8.57 \%$ & 0 & $8.57 \%$ & $9.3 \%$ & 0 & $9.3 \%$ & $0.6 \%$ & 0 & $0.6 \%$ & $0.14 \%$ & 0 & $0.14 \%$ & $0.54 \%$ & 0 & $0.54 \%$ \\
\hline 10 & $8.59 \%$ & 0 & $8.59 \%$ & $9.33 \%$ & 0 & $9.33 \%$ & $0.6 \%$ & 0 & $0.6 \%$ & $0.14 \%$ & 0 & $0.14 \%$ & $0.53 \%$ & 0 & $0.53 \%$ \\
\hline 12 & $9.12 \%$ & 0 & $9.12 \%$ & $9.37 \%$ & 0 & $9.37 \%$ & $0.59 \%$ & 0 & $0.59 \%$ & $0.14 \%$ & 0 & $0.14 \%$ & $0.54 \%$ & 0 & $0.54 \%$ \\
\hline 14 & $11.1 \%$ & 0 & $11.1 \%$ & $9.35 \%$ & 0 & $9.35 \%$ & $0.57 \%$ & 0 & $0.57 \%$ & $0.14 \%$ & 0 & $0.14 \%$ & $0.54 \%$ & 0 & $0.54 \%$ \\
\hline 16 & $17.07 \%$ & 0 & $17.07 \%$ & $18.3 \%$ & 0 & $18.3 \%$ & $0.57 \%$ & 0 & $0.57 \%$ & $0.74 \%$ & 0 & $0.74 \%$ & $4.48 \%$ & 0 & $4.48 \%$ \\
\hline
\end{tabular}

